\title{
Espaço e poder no principado romano: um estudo de caso sobre a fundação da colônia de Augusta Emérita entre os séculos I e II d.C. ${ }^{1}$
}

\author{
Airan dos Santos Borges*
}

BORGES, A.S. Espaço e poder no principado romano: um estudo de caso sobre a fundação da colônia de Augusta Emérita entre os séculos I e II d.C. R. Museu Arq. Etn., São Paulo, n. 23, p. 79-94, 2013.

Resumo: O presente artigo visa a analisar uma estratégia específica de intervenção no espaço utilizada pelo Império romano para a consolidação dos territórios conquistados, a saber, fundação de colônias. Diante da grande extensão do Império Romano, optamos por centrar nossas investigações no estudo da colônia de Augusta Emerita localizada na Província da Lusitânia, durante os séculos I a.C e II d.C. Seguindo os pressupostos teóricos de Henri Lefebvre, defendemos que esta colônia constituiu-se em um espaço característico do Império Romano no sudoeste da província da Lusitânia que correspondeu às concepções e experiências do espaço social específicas da sociedade romana.

Palavras-chaves: Império Romano, Principado, Augusta Emérita, Espaço social, Henry Lefebvre.I.

\section{Introdução}

Sabemos que, durante a República,

$\checkmark$ Roma expandiu seu domínio para além das fronteiras itálicas. As intervenções militares praticadas já no IV século a.C. e intensificadas nos séculos III, II e I a.C. fizeram com que a autoridade romana fosse aplicada primeiro na Península Itálica (nas intervenções no Lácio, Campânia, Magna Grécia) e, progressivamente, na região mediterrânica. Com estas interven-

(*) Doutoranda no Programa de Pós-Graduação em História Comparada da Universidade Federal do Rio de Janeiro (Bolsista Capes). <ead.airanborges@hotmail.com> ções, Roma deixou de ser uma cidade-estado clássica, passando para o patamar de uma legítima Cosmopólis (MENDES 2004:22).

Após a projeção da força representada pelo exército romano, a organização espacial das regiões recém-conquistadas mostrou-se estratégi-

(1) Este artigo é uma síntese da pesquisa de mestrado que resultou na dissertação: A organização do espaço social no Principado: um estudo de caso sobre a colônia Augusta Emerita entre os séculos I a.C. - II d.C., defendida junto ao Programa de Pós-Graduação em História Comparada, sob a orientação da Profa. Dra. Norma Musco Mendes em 2010. É importante ressaltar que este artigo contou com a indispensável leitura crítica da Profa. Dra. Claudia Beltrão (UNIRIO/PPGHC) e do Prof. Mestre Marcelo Fernandes de Paula (PPGHC). Aqui registro minha gratidão e admiração por ambos. Vale destacar que é de responsabilidade da autora as possíveis falhas e ausências bibliográficas do presente trabalho. 
Espaço e poder no principado romano: um estudo de caso sobre a fundação da colônia de Augusta Emérita entre os séculos I e II d.C.

R. Museu Arq. Etn., São Paulo, n. 23, p. 79-94, 2013.

ca na consolidação e manutenção do território dominado. As técnicas de domínio do território seguiram as exigências das conquistas, as especificidades locais e o contexto sócio-histórico dos acontecimentos. A ação do poder romano foi trabalhada através (do) conceito de territorium, não como um espaço geográfico, mas sim um espaço delimitado sobre o qual se exercia o poder de uma entidade política, administrativa e judiciária, isto é, como uma forma de apropriação do espaço que se fundamenta nas relações de dominação e autoridade.

A divisão das áreas em províncias e a subdivisão destas em civitates com estatutos político-jurídicos diferenciados constituíram-se em elementos presentes na ação oficial em praticamente toda a face ocidental do Império Romano. Desse modo, o impacto da conquista pôde ser evidenciado pelas mudanças na paisagem (urbana e rural) do território, pela formação de uma paisagem híbrida materializada pelas novas formas de relações sociais. Essas novas práticas possibilitaram que as bases de poder e de status sociais tipicamente romanos fossem reproduzidos nas províncias de forma diversificada de acordo com as distinções sociais e regionais (CLÉMENT 1999:110-113).

$O$ presente artigo visa a analisar uma das estratégias utilizadas pela oficialidade romana para a intervenção e consolidação dos territórios conquistados, a saber, a fundação de colônias. Diante da grande extensão do Império Romano, optamos por centrar nossas investigações no estudo de caso da fundação da colônia de Augusta Emerita localizada na Província da Lusitânia, no século I a.C.

Nesse estudo, dialogaremos com os pressupostos teóricos de Henri Lefebvre a respeito do espaço social, ao defender que a colônia emeritense constituiu-se em um espaço característico do Império Romano no sudoeste da província da Lusitânia que correspondeu às concepções e experiências do espaço social específicas da sociedade romana. Sua criação e desenvolvimento urbanístico interagiram com os vetores ideológicos fundamentais de legitimação do regime político do Principado e tornou-a capital cultural, centro de difusão da humanitas para as demais civitates da província.

\section{A teoria do espaço social de Henry Lefebvre e sua aplicabilidade no caso romano}

A teoria do espaço social proposta por Henry Lefebvre ${ }^{2}$ é construída sob a argumentação de que o 'espaço social' inclui o espaço físico-natural, assim como também as projeções, os projetos, os símbolos e utopias, característicos da sociedade que o formulou. Essa interpretação é redimensionada pela compreensão do espaço como produto social, na qual as sociedades produzem o seu de acordo e em consoante às próprias concepções de mundo.

A expressão 'produção do espaço' indica, então, um passo adiante na reflexão arquitetônica e urbanística, uma vez que ultrapassa setores tradicionais (como o político-econômico) ao ampliar-se para o conjunto do social. O espaço não é considerado como um dado a priori, fundamentalmente geométrico, objetivo e neutro, passando a ser visto como parte integrante do desenvolvimento da atividade social, como um instrumento político estrategicamente modelado a partir de elementos sócio-históricos, um produto da história.

Na obra The Production of Space, Lefebvre (1991:33) define três dimensões espaciais que dão forma ao espaço social como uma categoria de análise histórica:

a) a das práticas espaciais: relacionadas à produção e reproduções de conjuntos espaciais característicos de cada sociedade que asseguram certo grau de coesão. É a dimensão da materialidade, da concretude do espaço, das construções com as quais os homens habitam no seu cotidiano;

b) a das representações do espaço: são as concepções da sociedade que envolvem os conhecimentos que permitem compreender e ordenar as práticas materiais (tais como a geografia, a arquitetura e o planejamento);

(2) Sobretudo nas obras The Production of Space (edição de 1991) e Espaço e Política (tradução publicada pela editora da UFMG em 2008). 
c) a dos espaços representacionais: está relacionada à dimensão da vivência cotidiana, implicando os códigos, signos, símbolos, ou seja, os simbolismos das construções materiais que funcionam como espaços simbólicos, os quais criam novos sentidos e possibilidades para as práticas espaciais.

Essas diferentes dimensões (materialidade, concepção e vivência cotidiana) são complementares entre si e compõem uma ideia sobre o espaço social, ao mesmo tempo em que o produzem. Nessa abordagem, a produção do espaço também recebeu uma função simbólica e cultural, uma vez que se refere às hierarquias sociais e às visões de mundo presentes nas concepções arquitetônicas e nas práticas espaciais da sociedade que o modulou. Logo, a compreensão da produção das formas espaciais pressupõe o estudo da estrutura social que a contextualiza.

Outra questão que permeia o pensamento lefebureano consiste na argumentação de que a estrutura do espaço organizado não possui leis autônomas de construção e transformação, não é simplesmente uma expressão da estrutura de classes que emerge das relações sociais de produção. Contrariamente, ela representa um componente dialeticamente definido das relações de produção gerais, relações essas que são simultaneamente sociais e espaciais. Nessa leitura, as relações sociais e espaciais são dialeticamente inter-relativas e interdependentes, ou seja, na medida em que se considera o espaço organizado como socialmente produzido, entende-se que as relações sociais de produção são formadoras de espaço e contingentes a ele (SOJA 1993: 99-103).

Nessa reflexão, consideramos a proposta teórica de Lefebvre pertinente para a análise dos conhecimentos (geografia, arquitetura e planejamento) que definiram as representações e concepções espaciais da sociedade romana no período do Principado. Frente a isso, veremos como esses princípios foram aplicados tanto na organização da Província da Lusitânia quanto na fundação e consolidação da colônia de Augusta Emérita. Estabelecemos como recorte temporal o período do Principado por considerarmos que foi nesse momento que houve uma intensificação do processo de adaptação das áreas conquistadas à lógica territorial romana ${ }^{3}$. Para tanto, continuaremos nosso estudo estabelecendo como ponto de análise a seguinte questão: como podemos caracterizar a 'questão espacial' durante a instalação e ao longo do sistema político do Principado (I a.C./ II d.C.)?

\section{O Principado Augustano e a organização espacial}

O advento do Principado no I século a.C. esteve ligado às profundas mudanças ocorridas nas relações políticas e que deflagraram a desagregação do sistema de governo republicano e sua inadequação ao novo contexto trazido pelas conquistas. Diante dos objetivos deste artigo, limitar-me-ei a afirmar, parafraseando Claude Nicolet (1983:164), que o Principado representou uma conquista tripla: política, espacial e temporal. Dessa forma, entendemos que no bojo do processo de construção do Principado foram forjados novos sistemas de representação vinculados a uma nova identidade política, temporal e espacial.

Caius Octavius (que se tornou, por adoção, Caio Júlio César Otaviano e, posteriormente, César Augusto, o Augusto), fortalecido pela concentração em suas mãos da tribunicia potestas, do pontificatus maximus e do imperium majus, conquistou a legitimidade necessária para comandar as questões relativas à organização espacial. A conquista do espaço e as delimitações do mundo conhecido (oikoumene) foram apresentadas como intimamente ligadas ao novo tempo, criado e garantido pelo governante. Neste, Roma, ultrapassado o caos das guerras civis e pela vontade divina encontrava-se pronta para cumprir o seu destino: organizar e dominar o mundo conhecido.

(3) Para aprofundar essa questão ver: FUNARI, P. "Reflexões em torno da cidade romana”. In: BARBOSA, S. (Org.) Tempo, espaço e utopia nas cidades. São Paulo: Série Estudos Literários, n. 4, 2004; GRIMAL, P. As cidades romanas. Lisboa: Edições 70, 2003 E MACMULLEN, R. Romanization in the Time of Augustus. Yale University Press, 2000. 
Espaço e poder no principado romano: um estudo de caso sobre a fundação da colônia de Augusta Emérita entre os séculos I e II d.C.

R. Museu Arq. Etn., São Paulo, n. 23, p. 79-94, 2013.

No tocante à questão espacial, o estabelecimento do Principado por Otávio Augusto representou o momento de criação de uma política sistemática de organização das regiões, empreendendo a ampliação e intensificação da organização das áreas conquistadas, iniciada durante a República através de estratégias de integração e de ordenamento do espaço. A nova identidade política e temporal propiciada pelo Principado envolvia uma identificação espacial, caracterizada pela necessidade política de afirmar a submissão do mundo, organizar o território do Imperium, e programar a exploração sistemática das regiões conquistadas de acordo com os valores identitários da sociedade romana e sua concepção de mundo. Para tanto, a organização provincial e a estratégia das cidades (estabelecendo novas fundações ou retrabalhando núcleos urbanos prévios) configuraram-se em importantes recursos para essa reorganização.

De fato, no trato com as províncias, a nova política inaugurada por Otávio Augusto atuou de forma contundente, fazendo nascer uma divisão provincial de dupla tipologia: as províncias senatoriais e as imperiais. Por um lado as províncias senatoriais (ou do povo romano), governadas segundo a tradição republicana, isto é, tendo a frente um proconsul (de ordem pretória ou consular), com um quaestor e vários legati (o número variava de acordo com a província), cuja designação era anual e feita por sorteio. Ainda que, teoricamente, estas províncias seguissem dependendo do Senado e os impostos arrecadados fossem para o tesouro de Saturno, de fato, o Imperador poderia intervir nelas quando considerasse conveniente.

Em outro formato, estavam as províncias imperiais, administradas por 'delegados' do Imperador, com o título de legati Augusti pro praetore, igualmente de ordem consular e pretória. Nelas, não havia questores, mas sim procuradores, e em algumas, legati, como, por exemplo, na Hispania Tarraconense, que consistia no território de Asturia e Callaecia (entre os governos de Adriano e os Severos). Em todos os casos, a nomeação era realizada pelo Imperador, que poderia mantê-los no posto pelo tempo que fosse necessário, muito embora habitualmente os governadores permanecessem apenas três anos. Além disso, algumas províncias eram nomeadas pelo imperador a procuradores equestres e não a senadores, que como careciam de Imperium, tendo sob seu mando unicamente tropas auxiliares. Em um primeiro momento, receberam o título de praefectus e se encontravam sob a supervisão do governador senatorial de alguma província limítrofe ${ }^{4}$.

Nas províncias ocidentais, a prioridade foi consolidar a conquista e subordinar os povos, introduzindo a ética civilizatória e criando uma nova ordem (WOOLF 1995:144; 2005).

A administração do Imperium foi centralizada para atender às necessidades regionais, completada pela Romanização ${ }^{5}$ através das

(4) Aqui dialogamos com os estudos de MONTENEGRO DUQUE, A. História de España - Edad Antigua I: España Prerromana. Madrid: Gredos, 1972; WOOLF, G. "The Formation of Roman Provincial Cultures". IN: Integration in the early roman west: the role of culture and ideology. International Conference at the Titelberg, Luxembourg, November 1993, Luxembourg: Jeannot Metzler Ed., 1995 e RICHARDSON, J. S. Hispaniae: Spain and the development of the Roman imperialism 218-82 BC. Cambridge: Cambridge, 2004.

(5) O termo Romanização foi desenvolvido na Historiografia de fins do século XIX e início do século XX para explicar o contato entre os romanos e os outros povos. Buscava elucidar a forma como a adoção dos padrões estéticos, das práticas de consumo e de produção dos romanos foi encontrada nas províncias e nas regiões de fronteira do Império. Nesse período, são claros os paralelos entre o Império Romano e aqueles construídos pelas potências imperialistas do mundo moderno. No bojo destas primeiras reflexões, a experiência imperialista romana foi apropriada pelos discursos das potências coloniais que a utilizaram para justificar e legitimar o seu domínio e o seu 'direito de conquista’ sobre as nações Afro-asiáticas. Visto com admiração por intelectuais como Theodor Mommsen (1874), o Império Romano foi vinculado à ação imperialista das nações europeias que se entendiam como herdeiras de Roma. Essas legitimavam sua ação com o discurso de disseminar entre os nativos os padrões culturais da vida civilizada. Nessa leitura, ao difundir pelos 'nativos' a cultura clássica, Roma teria criado o contexto para o desenvolvimento da noção de civilização, responsável pela ligação entre o mundo antigo e o moderno. Esse tipo de abordagem denominada de corrente modernista marcou os estudos arqueológicos e as escavações nos sítios romanos, pois a teoria e a metodologia de análise utilizadas estavam baseadas na oposição binária entre categorias como: civilizado e primitivo, conquistador x conquistado . Ademais, nessas interpretações, o Império Romano fora definido como uma entidade homogênea e estática, cuja existência era atribuída à força coercitiva e a um 
cidades com modelo baseado em Roma (arquitetura e administração) que assumiu um aspecto essencial na consolidação das conquistas. $\mathrm{Na}$ concepção de mundo tardo-republicana, a cidade era interpretada como um elo intermediário entre o Estado e a família (Cícero, De Officiis, 1,7). A civitas reunia os fundamentos da educação, da moral, da administração, da vida jurídica e da política no mundo. No conjunto de valores caros à visão de mundo romana, o pertencimento à cidade consistia em um dos caracteres que distinguia os 'civilizados' dos selvagens/ bárbaros (Salústio, Conj.Cat.,6). Era à cidade, enquanto forma básica de vida coletiva que os romanos deviam a sua existência, sua grandeza, suas prerrogativas jurídicas e políticas. Ela era o espaço fundamental para o exercício da humanitas. Portanto, no bojo dos processos de Romanização, a fundação ou transformação de um aglomerado nativo em uma cidade seguindo os moldes 'romanos' constituía um ato capital do ponto de vista político-administrativo e, também, na divulgação da dinâmica urbana interna do modo de vida romano.

$\mathrm{Na}$ escala provincial, os principais promotores da divulgação do modo de vida romano foram os grupos de elites que se aproximavam

amplo conjunto de princípios organizacionais. Vinculou-se a isso, a lógica de uma Romanização progressista e uniforme, cujo conceito implica a idéia de transferência cultural, aculturação, entendida como o abandono da identidade nativa pela adoção da imagem romana como um ato positivo e deliberado. As cidades provinciais eram interpretadas como pequenas 'Romas' no interior das regiões conquistadas, nada mais que um specula (espelho) romano. Apesar de toda a discussão em torno do conceito, no presente estudo utilizamos o termo Romanização para designar os múltiplos processos de transformação socioeconômica, política e cultural que teve início com o relacionamento entre os padrões culturais de identificação do cidadão romano e a diversidade cultural provincial numa dinâmica de negociação bidirecional. Caracterizou-se, dessa forma, numa experiência de contrastes que possibilitou a criação de uma civilização imperial, marcada pela unidade e diversidade. Para um estudo aprofundado, vide: MENDES, N."Romanização: cultura imperial". In: PHOINÎX. Rio de Janeiro: Sette Letras, 1999, p. 307-325.; REVELL, L. Roman Imperlialism and Local Identities. New York: Cambridge, 2009; HINGLEY, R. O Imperialismro Romano: novas perspectivas a partir da Bretanha. São Paulo: Anablume, 2010; HINGLEY, R. Recreating coherence without reinventing Romaniza tion. In: DIGRESSUS, The internet journal for the Classical World, 2003, p. 11-119. da administração imperial através da prática da benemerência (ou evergeta), isto é, pelo financiamento de obras públicas com recursos privados ${ }^{6}$. Ressaltamos que a dinâmica da experiência imperialista romana foi baseada na existência de uma orientação econômica de interdependência das áreas conquistadas e em relações de poder fundamentadas na posição ativa do nativo/cidadão através da prática de cooptação das elites locais e de experiências relacionais que permitiram a diversidade?

Ao se deparar com culturas tão distintas, agrupadas sob a égide de seu domínio, a cultura romana desenvolveu estratégias que buscavam conhecer e consolidar o domínio de modo não coercitivo, mas que garantisse a dominação dos territórios e suas gentes. A ordenação do território conquistado, criando ou mantendo a cidade, constituiu-se em uma eficaz forma de manter a unidade de territórios distintos e assegurar o domínio. Nesse sentido, no período do Principado, o ideal da civitas enquanto o espaço formulado de/para as relações sociais foi 'ressignificado', ampliado e exportado para além da Península Itálica, servindo como um meio de consolidação das áreas conquistadas e como divulgação do modo de ser romano.

\section{A colônia Augusta Emérita e a constituição de um espaço social na Lusitânia}

Como em outras cidades provinciais que formavam o Império Romano ocidental, aproximadamente 2.000 anos nos separam do período inicial do desenvolvimento topográfico de Augusta

(6) Sobre o financiamento de obras públicas e a prática da benemerência, consultar os trabalhos de Javier Andreu Pintado, sobretudo o artigo: "Construcción pública y municipalización em la província Hispania Citerior: la época flavia”. In.: Iberia, n. 7, 2004, p. 39-75. Para a relação entre benemerência e a realização de espetáculos públicos, ver NOGALES BASARRATE, T. Espetáculos en Augusta Emerita: espacios, imágenes y protagonistas del ócio y espetáculo em la sociedad romana emeritense - Monografias Emeritenses 5. Mérida: Museo Nacional de Arte Romano, 2000, p. 33.

(7) Vide os trabalhos de Norma Musco Mendes, sobretudo o artigo "Romanização: cultura imperial". In: PHOINÎX. Rio de Janeiro: Sette Letras, 1999, p. 307-325; 
Espaço e poder no principado romano: um estudo de caso sobre a fundação da colônia de Augusta Emérita entre os séculos I e II d.C.

R. Museu Arq. Etn., São Paulo, n. 23, p. 79-94, 2013.

Emerita. Os edifícios que chegaram até nós estão ora parcialmente destruídos ou profundamente alterados pelas sucessivas fases históricas da cidade. Em virtude das subsequentes etapas históricas do núcleo urbano emeritense, o estudo sobre a infraestrutura urbana encontra uma dificuldade maior, uma vez que está mesclada ou coberta por construções posteriores. Nos limites deste artigo, focaremos nossas análises no estudo da fundação e constituição do espaço social na região ${ }^{8}$.

As investigações a respeito dos povoamentos anteriores ao domínio romano na região de Augusta Emérita fomentaram inúmeras pesquisas arqueológicas e topográficas nos anos 1980. Segundo o arqueólogo Juan Javier Enríquez Navascués (1997:30), as escavações resultaram na evidência de que não existem vestígios concretos que demonstram a existência de uma cidade pré-romana sobre a qual estava fundada a colônia. Todavia, os poucos artefatos encontrados evidenciaram a ocupação da região durante a Pré-História, sobretudo nos territórios próximos ao lugar no qual foi erigida a cidade romana. Frente a isso, as escavações buscaram avaliar se a área escolhida para a fundação possuía algum papel importante nos processos culturais anteriores ao domínio romano.

Como representado no mapa a seguir, as análises revelaram que a primeira ocupação estável da região é datada no período Calcolítico, com a presença de pequenos assentamentos ao redor da cidade atual (Mérida, capital da província da Extremadura Espanhola). Os vestígios apontam que na Idade do Bronze o território sofreu uma reorganização populacional com a consolidação de sistemas produtores agropecuários utilizando espécies domesticadas. Data-se nessa mesma época alguns artefatos atrelados ao prestígio social - como vasilhas, adagas de cobre com arremates e

(8) Nesse panorama, as pesquisas histórico-arqueológicas nos oferecem dados suficientemente estruturados e analisados para o desenvolvimento de nossa investigação. Torna-se essencial ressaltar que foi nas últimas décadas, com a fundação do Museo Nacional de Arte Romano e com as pesquisas apoiadas pela Junta de Extremadura e pelo Consórcio Ciudad Monumental Historico - Artística y Arqueológica da cidade de Mérida, que foi dado um novo impulso às pesquisas e a revisão dos estudos clássicos sobre o conjunto urbano - arquitetônico colonial. empunhaduras em ouro -, tais objetos indicam a possivel existência de elites locais de caráter guerreiro (PAVÓN, 1995; NAVASCUÉS 1997:35). Em alguns povoados ocupados durante o Bronze Final, detectou-se a produção de cerâmicas a torno, que agrupadas a outras peças funerário-rituais encontradas em necrópoles próximas ao rio Guadiana direcionam para o processo de orientalização das terras que formavam a periferia do núcleo tartésico.

Atualmente, apesar dos poucos dados conhecidos sobre a dinâmica geral do povoamento pré-romano da bacia média do rio Guadiana, os estudos de Rodríguez Díaz (1989; 1990; 1995 [a, b e c]) observam que a partir do século IV a.C. houve uma reorganização geral do povoamento com a utilização de novos lugares para habitat e com a continuidade de alguns povoamentos que possuíam valor estratégico nas principais áreas do rio já no período do Bronze Final. Segundo o autor, as características dos assentamentos, sua integração na paisagem, cultura material e atividades econômicas permitiram a configuração de uma série de círculos culturais que transformaram a região que recebeu Augusta Emérita em um lugar de encontro entre os grupos lusitano-vetão e túrdulo-turdetano.

A fundação da Colonia Augusta Emerita está circunscrita ao início do território da Lusitânia Extremenha, constituindo-se em elo intermediário entre a oficialidade romana e o meio indígena do sudoeste peninsular. Seu estabelecimento foi ordenado pelo Imperador Augusto no ano 25 a.C. 9 (729 de Roma), ao final da guerra contra os Cântabros e Ástures ${ }^{10}$. Esta guerra foi emblemática pelos intensos combates contra as instáveis tribos nortenhas. Seu término contribuiu para a pacificação do território, a intensificação da exploração de importantes minas de ouro e para a submissão total da Península ao domínio romano. Através das cunhagens monetárias emitidas por Publio Carisio, lugar-tenente de Augusto e fundador

(9) Vide o texto de Antonio Marques de Faria em crítica ao posicionamento de Alicia Canto na Revista Portuguesa de Arqueologia, volume 1, número 1,1998.

(10) Dião Cassio, 54, 23, 7, Vide a análise de Giovanni Forni La popolazione di Augusta Emerita (1982). 
da colônia ${ }^{11}$, sabe-se que na nova cidade foram assentados os soldados veteranos das legiões ${ }^{12} \mathrm{~V}$ Alaudae e X Gemina - ambas combateram nas guerras do norte, ao lado de mais cinco legiões e suas correspondentes tropas auxiliares ${ }^{13}$.

A colônia foi fundada quase no curso médio do extenso vale do Anas (atual rio Guadiana), em sua margem direita. Nessa região, o rio corre limitado por montanhas que dividem seu vale em duas partes igualmente férteis, planas e abertas: a hoje denominada Vegas Altas, ao leste de Mérida, e as Vegas Bajas, que se estendem até o oeste da cidade, até Badajoz. Na região escolhida para a colônia a corrente do rio, suavizada pelo vale, oferece uma pequena ilha que divide o leito e facilita a passagem (ALMAGRO-BASCH 1976:191). Essa geografia facilitou a construção da ponte no mesmo período da fundação da cidade (ÁLVAREZ MARTINÉZ, 1988). No desenvolvimento da colônia, a ponte (imagens 2 e 3) teve um papel fundamental, uma vez que vencia o rio e interligava a região com as áreas vizinhas ao facilitar o comércio do sul e o norte peninsular, integrando e cruzando antigas estradas com os trajetos econômico-militares. Através das estradas interligadas pela ponte, chegava-se à desembocadura do rio Guadalquivir na antiga Hispalis; à Itálica, primeira fundação romana na Hispania em 207 a.C., e ainda ao porto de Cádiz, porta do Mar Mediterrâneo.

(11) Consultar as cunhagens publicadas no primeiro volume do Roman Provincial Coinage. From de death of Caesar to the death of Vitellius (44 bC - AD 69), editado por Andrew Burnett, Michel Amandry e Pere Pau Ripollès, Paris/ Londres 1992, parte II: Indexes and Plates. São as moedas de número 1 a 50. Ainda sobre o assunto, outro importante (e recente) manual foi editado por Christopher Howgego, Volker Heuchert e Andrew Burnett, Coinage and Identity in the Roman Provinces, Oxford, 2005.

(12) Sobre este assunto, Farias aponta os posicionamentos de Keppie (1983, p. 83, n. 146), para o qual: «[t]hree veterans of a legion XX are attested at Emerita within the Augustan period (CIL II 22*,662, 719). These cannotbe colonists of 25 B.C., who were drawn from legions $V$ and $X$, but could document a later reinforcement». No entanto, Farias ressalta que esta mesma hipótese já fora aventada por Wiegels (1976, p. 272), que, paralelamente, não deixou de contemplar a eventualidade de um pequeno contingente de licenciados da legião XX ter participado na fundação da colônia em 25 a.C. ao lado dos veteranos das legiões V e X. Vide: Dion Casio (História de Roma 53:25, 2).

(13) Alguns pesquisadores ainda incluem a XX Victrix.

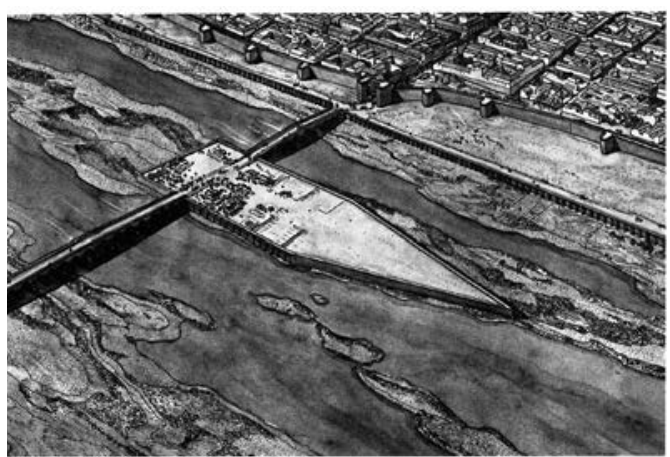

Imagem 1 - Desenho ideal da área do rio Ana, com a ponte e o 'quebra-mar', segundo Golvin-Álvarez-Nogales ${ }^{14}$.

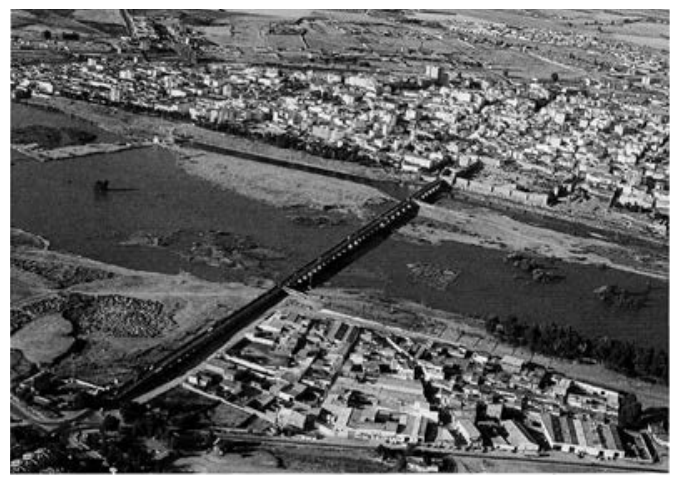

Imagem 2 - Foto aérea do rio, fachada urbana da colônia e ponte romana sobre o rio Guadiana ${ }^{15}$.

Do ponto de vista territorial, as transformações da região interagiram com a reorganização provincial realizada por Augusto - de caráter político e administrativo. Com a divisão da antiga província da Hispania Ulterior e a criação das províncias da Lusitânia e Bética (27 a.C.), Augusto reestruturou o território, modificando a paisagem indígena. A fundação de Augusta Emérita, em 25 a.C., se insere nessa política ao ser criada para ser o centro nuclear dentro da região e substituir a antiga intercessão viária local. A nova colônia herdou o papel que Metellinum

(14) Fonte: NOGALES-BASARRATE, T. Espectáculos em Augusta Emerita - Espacios, imágenes y protagonistas del ócio y espectáculo em la sociedad romana emeritense - Monografia Emeritenses 5. Mérida: Ministério de Cultura/MNAR/Fundación de Estudios Romanos, 2000, p.136.

(15) Disponível no estudo de NOGALES-BASARRATE, T. op. Cit, p.136. 
Espaço e poder no principado romano: um estudo de caso sobre a fundação da colônia de Augusta Emérita entre os séculos I e II d.C.

R. Museu Arq. Etn., São Paulo, n. 23, p. 79-94, 2013.

exerceu como base para as lutas entre Metelo, Sertório e os Lusitanos, passando a ser o núcleo central da presença romana em um ponto estratégico do rio Anas. Sua fundação estava diretamente ligada ao programa de fundações que Augusto desenvolveu na península; em etapas progressivas, tendo como meta essencial planejar a organização administrativa e a ampliação das redes de comunicações e defesa do território.

Concordamos com Giovanni Forni (1982:73), seguido por Manuel Salinas de Farias (1998: 161-167) e Patrick Le Roux (2004: 263-265), ao considerarmos que embora Augusta Emerita fosse fundada pelos veterani emeriti de Augusto, os soldados vitoriosos do Imperador, a presença de veteranos na região não atribuía à colônia uma vocação militar. Simbolizava, claramente, pela manutenção de longos tempos de paz, um diálogo intenso com a representação imperial formulada por Augusto, esta sim, fundamentada e baseada na vitória e no triunfo de Roma. Sua criação em meio a uma região que fora palco de inúmeros conflitos militares, seria um marco testemunhal da glória romana. Tese semelhante é defendida por Francisco Germán Rodríguez Martín (2004:121127) que, baseado em Dion Cásio, Tácito, Higino e Agennio Urbico, aponta que depois da fundação da colônia iniciou-se um processo de povoamento da região por colonos itálicos e a repartição das terras às margens do rio Guadiana.

Sua fundação seguiu o cerimonial romano tradicional composto por distintas fases, a saber: inicialmente o finitor consultava os auspicia e, através destes, fixava o lugar definitivo da inauguratio 16. Fazia-se delimitação

(16) O ritual da Inauguratio era uma das atribuições do colégio dos áugures, um dos mais importantes colégios sacerdotais durante a República Romana. Vinculados a Júpiter, entre o conjunto de atribuições desses sacerdotes estavam a definição e manutenção das fronteiras entre o divino e o humano. Suas ações estavam vinculadas às ações dos magistrados que envolviam tanto a inauguração de pessoas através da aquisição de seus títulos na vida pública, quanto à inauguração de espaços da urbs. Sobretudo no tocante às determinações territoriais, os rituais que compunham a inauguratio eram responsáveis pela separação da zona augural das outras zonas que compunham a cidade, além de separar os tipos de terras. Como indica Cícero, as ações dos áugures na inauguratio atuavam "liberando e desobstruindo a cidade, os campos e os templa” (Leg. 2.8.21). dos limites externos e as divisões internas dos quarteirões da futura cidade, aqui também era demarcado o lugar sagrado (pomerium), uma vez que assinalava o local das domi, separado das militia17. No caso emeritense, a ponte serviu como referência para o traçado, ao centrar o recinto e demarcar uma linha que se prolongava para o leste, indicando a orientatio da rua principal, o decumanus maximus, com ela cruzava perpendicularmente a via que ia de norte a sul, kardo maximus, deslocado em $30^{\circ}$ do norte geográfico (CORZO 1976: 216). Era o cardo que separava a regio antica ou citrata da regio postica ou ultrata do perímetro urbano. O fórum da colônia foi construído na intercessão das principais vias. Em paralelo as vias principais, foram marcadas as ruas secundárias, formando os 'bairros' retangulares (insulae), de traçado reticulado e hipôdamico, que resultaram em dois lados maiores em direção ao kardo, isto é, na disposição denominada per strigas. As ruas foram pavimentadas com diorita azul proveniente de Garrovilla, uma pequena região atualmente localizada alguns quilômetros da atual Mérida, parte das ruas principais e mais movimentadas eram identificadas por pórticos.

A muralha colonial que demarcava o perímetro urbano em toda a sua extensão era constituída por torres e bastiões que seguiam formatos distintos e apresentavam datações variadas: os situados próximos ao rio Anas e na área do Anfiteatro são datados em épocas augusteas; já as torres encontradas nas ruas José Ramón Mélida e Calvo Sotelo (na atual trama urbana da cidade de Mérida) e a que corresponderia à entrada principal da colônia, apresentam uma planta arredondada e datação em meados do I século d.C. (SÁENZ-BURUAGA, A. 1954; ALVAREZ MARTINÉZ, J. 1971 e BERROCAL RANGEL, L. 1987:42).

(17) Para uma descrição aprofundada sobre a temática dos ritos de fundação, indicamos o rico artigo da Profa. Dra. Claudia Beltrão, intitulado Terminatio e Limitatio: inauguração, fundação e cena ritual na República Romana, que aguarda publicação. 


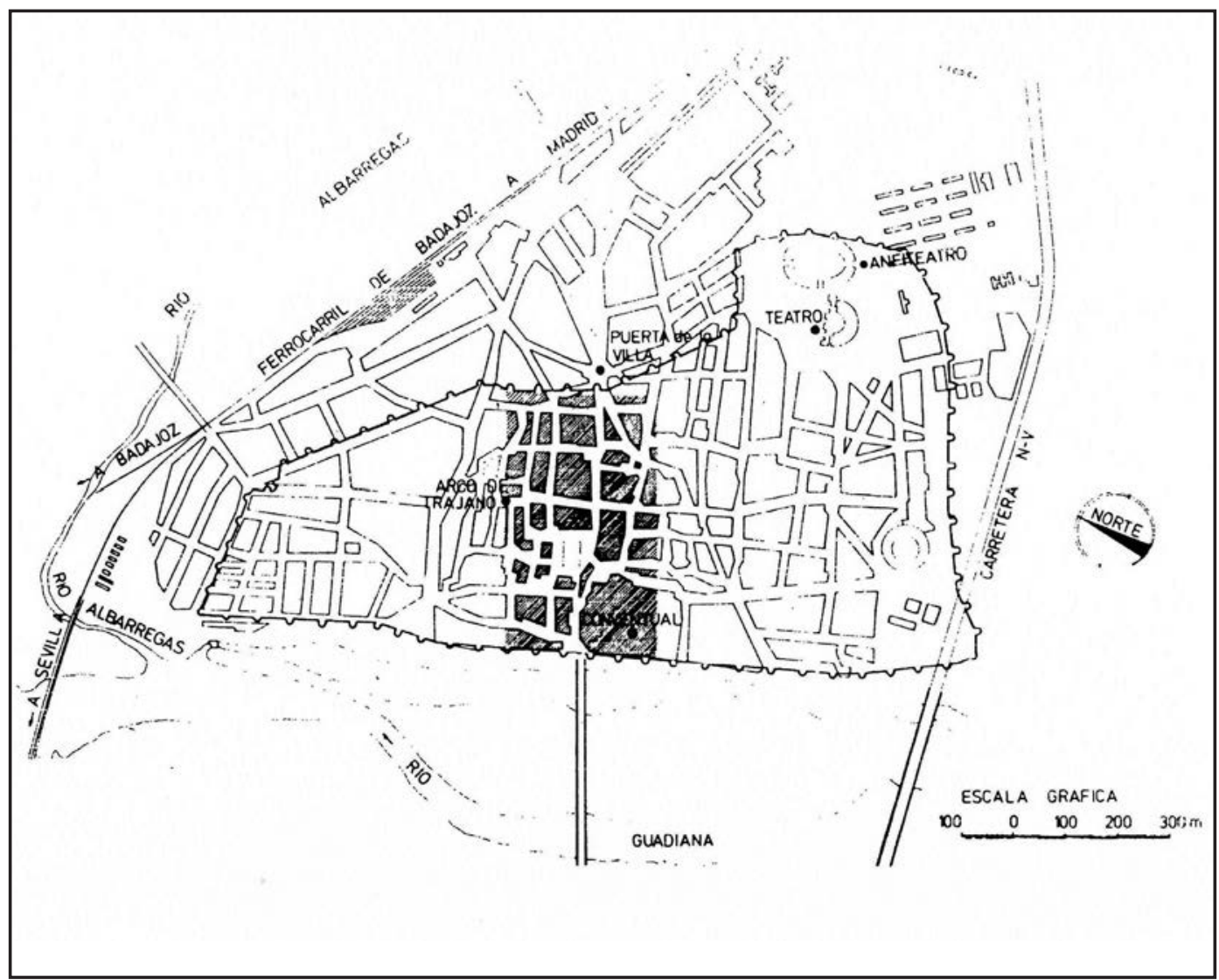

Imagem 3 - Planta do plano urbano com a muralha colonial ${ }^{18}$

Seguindo a tradição romana, Emérita possuía quatro portas principais localizadas nos extremos das vias principais, das quais saíam as principais estradas que atravessavam o perímetro colonial: uma situada a leste, outra a oeste, uma ao sul e outra ao norte da cidade. A porta norte, que dava acesso à ponte sobre o rio Anas, seguia uma formatação com um duplo vão de passagem ${ }^{19}$. De acordo com os estudos

(18) Plano de Mérida com o traçado da muralha romana com a demarcação do núcleo primitivo da cidade. Fonte: DURÁN-CABELLO, R-M. El Teatro y el Anfiteatro de Augusta Emerita: contribuición al conocimiento histórico de la capital de Lusitania. Oxford: BAR International Series 1207 / Archaeopress, 2004, anexos.

(19) Algumas moedas datadas nos primeiros anos da colônia fazem alusão a esta porta em suas representações. Na parte II (Index and Plates) do primeiro volume do Roman Provincial Cainage (44 a.C. - 69 d.C.), 1992; corresponde aos numismas de Alvarez Martínez (1982), interpreta-se que tal formatação correspondia com uma necessidade de viabilizar o tráfego da saída da ponte, ou seja, corresponderia a uma porta de entrada e outra de saída.

Como demonstra o mapa de Corzo Sánches (1976:217) abaixo, o elo das coordenadas da colônia foi formado pelo kardo maximus (caminhos 2 e 6) е о decumanus maximus (caminhos 4 e 8). Os caminhos resultaram de uma planificação que tinha como meta realizar a formação de um elo de coordenadas e marcos geográficos, com base para a orientação do território circundante. Encontramos uma organização territorial planificada que culminou na fundação da colônia.

de número $10,12,20,21,2,23 / 16,23 / 17,24,25,27,30$, 31/1, 31/4, 32, 33, 38, 41, 42/15, 42/66, 43 e 44. 
Espaço e poder no principado romano: um estudo de caso sobre a fundação da colônia de Augusta Emérita entre os séculos I e II d.C.

R. Museu Arq. Etn., São Paulo, n. 23, p. 79-94, 2013.

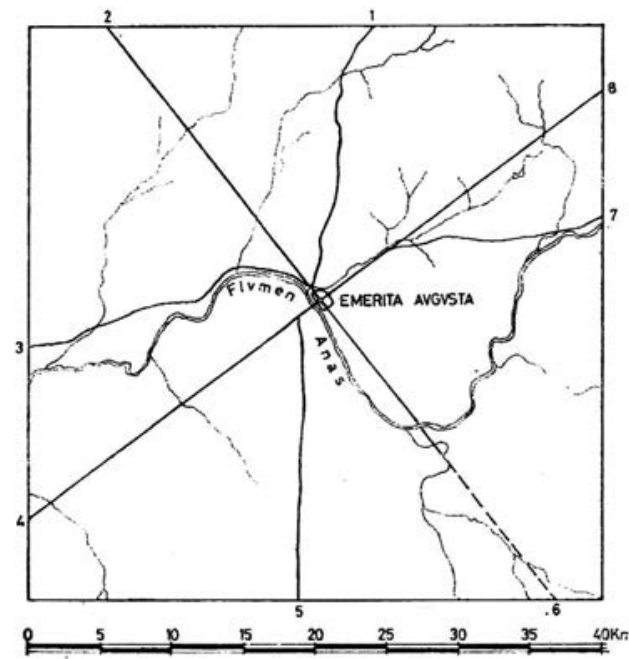

Imagem 4 - Mapa do entroncamento de rotas no território colonial, segundo Corzo Sanchez20

A demarcação das terras foi feita pelo sistema geométrico, seguindo o decumanus e o kardo da cidade a partir dos quais se efetuou a divisão do território em parcelas, ou seja, sua centuriação. As distribuições foram realizadas de acordo com a qualidade das terras (secundum bonitatem agrorum) e de acordo com a hierarquia militar dos colonos (secundum gradus militiae) e por seus méritos (pro mérito) (SAQUETE - CHAMIZO, J., 1997:51). Através dos relatos de Hygino (De limit. Const., 135), sabe-se que os terrenos próximos ao decumanus tinham 40 actus de largura e os próximos ao kardo, 20. Cada centúria tinha 400 iugeras em lugar dos habituais 200. Assim, a centúria de Emérita foi de 710 por 1.420 metros quadrados, um caso incomum na região ${ }^{21}$. Como indica Frontino (De contr. Agr. 37, 13), a planificação não alcançou toda a superfície do terreno, algumas áreas permaneceram

(20) Fonte: CORZO-SANCHEZ, D.R. 'In finibus emeritensium'. In.: BLANCO FREIJEIRO, A. (org). Augusta Emerita: actas del simpósio internacional commemorativo Del bimilenário de Mérida. Madrid: Ministério del Patrimonio Artistico y Cultural del Ministério de Educación y Ciencia / Patronato de la ciudad de Mérida, 1976, PP.217.

(21) O tema da excepcionalidade do território emeritense foi tratado em um excelente estudo realizado por Walter Trillmich "Los três foros de Augusta Emerita", In.: LEÓN, P. (edt), Colonia Patricia corduba-uma reflexión arqueológica. Coloquio Internacional. Córdoba: Junta de Andalucía, 1993. desocupadas para dar lugar a pastos e bosques públicos consagrados à deusa Feronia, com cerca de 250 hectares $^{22}$; igualmente as terras situadas próximas ao rio constituíram as terras livres e públicas.

Analisando os dados arqueológicos, Rosália-María Durán Cabello (2004:55) aponta que atualmente é defendida a tese de que a fundação de Augusta Emérita partiu de um núcleo primitivo mais reduzido e foi crescendo e remodelando-se como consequência do aumento demográfico. Em decorrência desse incremento surgiram novas necessidades urbanísticas que deviam ser solucionadas pela administração romana. Uma dessas soluções consistiu na subdivisão do território emeritense em áreas administrativas submetidas à administração geral da colônia.

Para a administração de um território tão vasto, foram criadas três praefecturae (Hyg. De limit. Const., 136), das quais são conhecidos os nomes de duas: a Turgaliensis, em Turgalium (Trujillo) e a Mullicensis (localizada por Canto [1989:176] na atual Montemolín). Em relação aos limites coloniais, seguindo os estudos de Álvarez-Martinéz (1993:135), podem-se apontar os seguintes: ao sul, os territórios das civitates dos conventus cornubensis e hispalensis: Lacinimurga Constantia Iulia, Iulipa (?), Municipium Iulium (Azuaga), Regina, Curiga-Contributa, Nertobriga Regina, Curiga-Contributa, Nertobriga e Seria. Ao norte, o campo norbense; na zona oriental, Valdecaballeros; e no ocidente Borba Estremoz, confluindo com o território de Ebora. Dentro do amplo território emeritense foram agrupados importantes núcleos populacionais, interligados à colônia por estradas (oficiais e secundárias) dos quais, se destacam Lacipea, Rodacis, Geraea, Contosolia, Caspiana, Perceiana, Cauliana, Evandriana, Turgalium, ad Sores.

Na colônia confluíam as estradas do sudoeste da Lusitânia, formando um amplo sistema de comunicações através do qual se organizou todo o território colonial, tendo naquela o núcleo de intercessão. Para tanto, duas pontes,

(22) Garcia-Bellido (1991, 73-75) localizou-a na área de Montánchez-Alcuéscar. 
em conjunto com a ponte sobre o rio Guadiana, realizavam a integração da colônia com as vias de circulação 'intercolonial'. Uma construída sobre o rio Albarrengas que dava saída para as estradas do norte e oeste desde o cardo máximo (ainda que menor, sua arquitetura e monumentalidade mostram ser contemporâneas à ponte do Anas). A terceira ponte, popularmente denominada de 'Alcantarilla Romana', se localiza fora da cidade, cerca de 2 quilômetros a oeste, servindo para permitir o acesso às estradas em direção a Olisipo (atual Lisboa) (BERROCAL-RANGEL 1987:45). Segundo Álvarez-Martinéz (1993:133), as estradas seguiam quatro princípios fundamentais: consistiam em uma forma de comunicação segura com as regiões mineiras do noroeste; eram uma rota de saída para o mar pelos portos naturais da costa atlântica, uma vez que o Rio Anas só era navegável em Myrtilis; consistiam em um rápido acesso ao Rio Guadalquivir e ao Mar Mediterrâneo, além de ser uma saída para Meseta.

Em meio às demais civitates que compunham a província da Lusitânia, Augusta Emérita se destaca pelo caráter monumental de seu urbanismo desde a fundação, no ano de 25 a.C. A colônia é um exemplo emblemático, uma vez que o próprio nome pressagia e proclama a ideia de que a força militar já se revelava desnecessária nessa parte do mundo, já imersa na Pax Augusta e amparada por ela (TRILLMICH 1998:165). Desde os primeiros anos, a colônia foi dotada de uma infraestrutura urbanística constituída por muralhas, muros de contenção do rio Anas, duas pontes (sobre o Anas e o Alvarengas) e, inclusive, edifícios dedicados ao ócio, como o teatro e o anfiteatro, doados por Augusto e Agripa em finais do século I a.C. Trata-se de construções que, espalhadas pela cidade, manifestaram a política urbanística adotada pelas cidades a partir de Augusto.

Como indica Trinidad Nogales Basarrate (2000 21:22), na primeira fase edilícia da colônia, foi construída a infraestrutura cidadã e caracterizada pelo emprego do granito nas construções, pela delimitação do perímetro murado, a demarcação das ruas, o planejamento e construção do sistema de cloacas, aquedutos e a construção da ponte sobre o rio Guadiana. Continuando a planificação inicial, foi realizada uma segunda fase construtiva na qual foram projetados os edifícios de espetáculo: o teatro e o anfiteatro. A marmorização dos edifícios monumentais, realizada por artistas especializados trazidos da Itália, aconteceu nos últimos anos do reinado de Cláudio e nos primeiros do filho de sua esposa, Nero (que fora adotado por Cláudio), isto é, já na última etapa da dinastia Júlio-Cláudia.

\section{Conclusões}

Nosso estudo nos permitiu observar que na experiência imperialista romana o fenômeno urbano foi expandido, na medida em que Roma foi reafirmando sua condição de potência dominadora, isto é, ao estender seu Imperium em praticamente todo o mundo conhecido.

Como demonstrado, a prática de fundação de cidades foi um vetor de divulgação do sistema de valores caros à identidade romana para todo o mundo conquistado, um veículo de Romanização. Contudo, entendemos que a cultura imperial cêntrica representada pelas cidades não foi imposta aos provinciais de forma homogênea. Os testemunhos arqueológicos apresentam uma grande diversidade de usos e interpretações que variaram de acordo com as diferenças provinciais e os diferentes momentos históricos. Em meio à pluralidade das cidades romanas, a organização social do espaço de acordo com as concepções romanas constituiu-se em um elemento comum às cidades, muito embora, em alguns casos, os "novos símbolos" permanecessem lado a lado com as tradições locais ou fosse adaptado às especificidades de cada terreno.

Como buscamos demonstrar, a fundação da colônia de Augusta Emérita, no período em estudo, seguiu as concepções de espaço características da cultura mediterrânica, configurando-se como um "espaço social romano" no sudoeste da Península Ibérica, na província da Lusitânia. Por conseguinte, a colônia sintetizou um duplo discurso: de integração e de poder. Um discurso de integração ao dar coesão a 
Espaço e poder no principado romano: um estudo de caso sobre a fundação da colônia de Augusta Emérita entre os séculos I e II d.C.

R. Museu Arq. Etn., São Paulo, n. 23, p. 79-94, 2013.

toda organização social, econômica, político-administrativa e cultural do sistema de domínio romano na região do sudoeste peninsular e um discurso de poder por intensificar os processos de identificação, identidade, produção, consumo, regulação na região dominada, viabilizando o processo de interação comunicacional entre os "outros".

As ações no espaço colonial fizeram parte do processo de construção de uma paisagem imperial que se caracterizou pela introdução de novas formas de ordenamento e intervenção no espaço, pela criação de novas formas de relações sociais que variavam de acordo com as potencialidades locais e o nível de complexidade social de suas populações. Esse fato corroborou com a representação imperial formulada pelo Princeps, baseada na vitória e no triunfo de Roma; nesta lógica, a fundação da cidade de Emerita em meio a uma região que fora palco de inúmeros conflitos militares, seria um dos testemunhos dessa ideologia de paz e vitória.
Nesse sentido, a fundação da cidade evidenciaria um novo programa de administração dos territórios conquistados implementado pelo soberano, programa este que, em longo prazo, foi baseado na divulgação dos valores caros à tradição romana através da reprodução dos marcos arquitetônicos e urbanísticos caros à VRBS Roma. Ao receber distintos contingentes populacionais quando da sua fundação, Augusta Emerita funcionou como uma capital cultural, vetor de difusão da humanitas para as demais civitates da província. Sua consolidação urbanístico-arquitetônica correspondeu às representações e experiências do espaço social específicas da sociedade romana, pois significou uma tripla estratégia de ordenação territorial por parte do centro imperial: (1) a centralização política e administrativa na futura província da Lusitânia; (2) a integração econômica local, interprovincial e imperial; e (3) apontou para a construção do espaço social, isto é, para a consolidação de uma nova concepção de território e estruturação do espaço social.

BORGES, A.S. Space and power in the roman principate: a study about the foundation of the colony of Augusta Emerita between 1 b.C. and 2 a.D. R. Museu Arq. Etn., São Paulo, n. 23, p. 79-94, 2013.

Abstract: This article aims to analyze a specific space intervention strategy used by the Roman Empire for the consolidation of conquered territories, namely founding colonies. Given the vast extent of the Roman Empire, we chose to focus our investigations on a study about Augusta Emerita, a colony located in the province of Lusitania, between $1 \mathrm{BC}$ and $2 \mathrm{AD}$. Following Henri Lefebvre's theoretical assumptions, we argue that this colony constituted a characteristical space of the Roman Empire in southwest Lusitania province, which corresponded to specific views and experiences of the Roman society social space.

Keywords: Roman Empire, Principality, Emerita Augusta, Social space, Henry Lefebvre 


\section{Referências Bibliográficas23}

\section{Documentação Textual}

CICERO.

1990 De legibus. The loeb Classical Library, vol. XVI. Harvard: University Press.

1990 Des Res Publica. The Loeb Classical Library, vol. XVI. Harvard: University Press.

DION CASIO.

2004 Historia Romana - Tomos I e II. Madrid: Gredos.

ESTRABÃO

1994 Cosmographia, 2.5.8 Apud W HITTAKER, C.R. Frontiers of the Roman Empire. A social and economic study. London: Johns Hopkins University Press. p.12ss.

FLORUS

1984 Epitome of Roman History. Harvard: Harvard University Press.

GUERRA, A.

1995 Plinio-o-Velho e a Lusitânia. Lisboa: Colibri, 1995 (coleção Arqueológica e História Antiga.

PLÍNE L'ANCIEN.

1998 Historie Naturelle (Livre IV). ZEHNACKER, H (trad.) Paris: Les Belles Letters.

POLIBIUS

1996 Historias. Tradução de Mario da Gama Kury. Brasília: UNB.

VITRÚVIO.

2007 Tratado de Arquitetura. São Paulo: Martins Fontes.

\section{Documentação de cultura material}

CEBAllOS - HORNEIRO, A.

2004 Los Espetáculos em la Hispania Romana: la documentación epigráfica (cuadernos emeritenses número 26). Mérida: Museo Nacional de Arte Romano/ Asociación de Amigos del Museo/ Fundación de Estudios Romanos.

(23) Nesta seção optamos por inserir apenas as referencias bibliográficas citadas diretamente na redação do texto ou que foram imprescindiveis no estudo da questão proposta. Para a bibliografia completa, favor entrar em contato com a autora.
JUNTA DE EXTREMADURA/ CONSEJERIA DE CULTURA Y PATRIMONIO.

1994 Conjunto Arqueologico de Merida: patrimonio de la humanidad. Extremadura: Junta de Extremadura.

RAMIREZ SÁBADA, J.

2003 Catálogo de las inscripciones imperiales de Augusta Emerita (Cuadernos emeritenses 21). Mérida: Museo Nacional de Arte Romano: Asociación de Amigos del Museo: Fundación de Estudios Romanos.

\section{Bibliografia Instrumental}

LEFEBVRE, $\mathrm{H}$.

1991 The Production of Space. Oxford/ Cambridge: Blackwell.

2008 Espaço e Política. Belo Horizonte: UFMG.

LIMONAD, E.

1999 Reflexões sobre o espaço, o urbano e a urbanização. In: GEOgraphia, ano 1, número I, pp. 71-91.

SAID, E.

1995 Cultura e Imperialismo. São Paulo: Companhia das Letras.

SOJA, E.

1993 Geografias Pós-Modernas: a reafirmação do espaço na teoria social critica. Rio de Janeiro: Jorge Zahar.

TRIGGER, B.

2004 História do pensamento arqueológico. São Paulo: Odysseus.

\section{Bibliografia Específica sobre a História}

Romana e Romanização

DAVIDSON, J.

2004 A construção de um espaço para o Império Romano: arquitetura, monumentos e ordenamento espacial. 2004. 298f. Tese de Doutoramento (Doutorado em História) - Programa de Pós-Graduação em História, Universidade Federal Fluminense, Niterói.

FUNARI, P.

2004 Reflexões em torno da cidade romana. In.: BARBOSA, S. (Org.) Tempo, espaço e utopia nas cidades. São Paulo: Série Estudos Literários, n 4.

GIARDINA, A.

1994 L'identità incompiuta dell'Italia romana. 
Espaço e poder no principado romano: um estudo de caso sobre a fundação da colônia de Augusta Emérita entre os séculos I e II d.C.

R. Museu Arq. Etn., São Paulo, n. 23, p. 79-94, 2013.

In.: L'italie d'auguste à Dioclétien. École française de Rome, Roma: Palais Farnèse.

MENDES, N.

1997 Limes Reno-Danubiano: conceito e prática no alto Império. In: PHOINÎX. Rio de Janeiro: Sette Letras.

1999 Romanização: cultura imperial. IN: PHOINÎX. Rio de Janeiro: Sette Letras.

2005 BUSTAMANTE, R. \& DAVIDSON, J., Experiência Imperialista Romana: Teorias e Práticas. Revista Tempo, Rio de Janeiro, v. 18, p. 17-41. . E SILVA, G.

2004 Império, poder e representação. In.: Dimensões - Revista de História da UFES, n. 16, CCHN; Vitória.

2004 Império e Latinidade. In: COSTA, D. E DA SILVA, F. (Orgs.) Mundo Latino e Mundialização. Rio de Janeiro: Mauad. . E SILVA, GILVAN. (ORGS.)

2006 Repensando o Império Romano: Perspectiva sócioeconômica, política e cultural. Rio de Janeiro: Mauad.

2008 O conceito de Pax Romana In.: ZHEBIT, A. (Org.) Ordens e Pacis: abordagem comparativa das relações internacionais. Rio de Janeiro: Mauad: 145-158.

2010 Ócio: "o que podem nos dizer os romanos?” In. MELO, V. (Org.) Lazer: olhares multidisciplinares. Campinas: Alínea.

NICOLLET, C.

1999 Space, Geography and politics in the early Roman Empire. Michigan: Michigan University Press.

1983 L'Empire Romaine: espace, temps et politique. Ktema, Strasbourg, v. 8:163-173.

WOOLF, G.

1995 The Formation of Roman Provincial Cultures. IN: Integration in the early roman west: the role of culture and ideology. International Conference at the Titelberg, Luxembourg, November 1993, Luxembourg: Jeannot Metzler Ed.

1996 Monumental Writing and the Expansion of Roman Society in the Early Empire. IN: The Journal of Roman Studies, vol. LXXXVI: 22-39.
1998 Becoming Roman. Cambridge: Cambridge University Press.

2001 The Roman Cultural Revolution in Gaul. IN: KEAY, S. and TERRENATO, N.: Italy and the West: comparative issue in Romanization. Oxford: Oxbow Books: 173-186.

2005 Provincial Perpective. IN: GALINSKY, P. (Edit.) The Cambridge Companion of the age of Augustus. Cambridge University Press: 106-129.

Bibliografia Específica sobre a Província da Lusitânia e a colônia de Augusta Emerita

ALARCÃO, J. (COORD.)

1990 Nova história de Portugal: Portugal das origens à Romanização. Lisboa: Editorial Presença.

ÁLVAREZ MARTINÉZ, J-M.

1982 El foro de Augusta Emerita. In.: Homenaje a Sàenz de Buruaga. Badajóz: s/e: 53-68.

2002 Calzadas de Hipania: planificación e ideologia imperial. In.: GALLIAZZO, V. (Org.) Atti del Convegno Internazionale/Beritche der Internationalen Tagung Via Claudia Augusta. Un'arteria alle origino dell'Europa: ipotesi, problemi, prospettive/Eine Strass am Ursprung. Europas: hypothesen, problem, perspektiven, feltre 24-25 Settembre/September 1999. Veneto: Comune di Feltre.

1971 El genio de la colonia Augusta Emerita. In.: Habis 2: 257-261.

1988 Algunas observaciones sobre el 'territorium emeritense' In.: Homenaje a Samuel de los Santos. Murcia: Albacete: 185-192.

1993 Ciudades Romanas de Extremadura. Barcelona: s/e: 129-159.

ALMAGRO BASCH, M.

1976 La topografia de Augusta Emerita. In.: Bimilenario de la colonia Caesaraugustana (vol. 1). Zaragoza: Universidad de Zaragoza.

BALIL, A.

1976 Las ideas urbanísticas en época agustea. In.: Bimilenario de la colonia Caesaraugustana (vol, 1). Zaragoza: Universidad de Zaragoza. 
BASARRATE, T. \& GORGES, J. - G.

2000 Sociedad y Cultura em Lusitania romana IV Mesa Redonda Internacional. Mérida: M.N.A.R.

BENDALA GALÁN, M.

1998 La paz augustea y la romanización. In. (s/a) Hispania: el legado de Roma. Zaragoza: Ministério de educación y cultura.

BERROCAL RANGEL, L.

1987 La urbanistica de Augusta Emerita (I e II). In. Revista de Arqueologia $n^{\circ} 71$ e 72, Madrid: 36-45 e 29-39.

CANTO, A.

1989 Colonia Julia Augusta Emerita: consideraciones en torno a su fundación y territorio. In: Gerion, Madrid, 7: 149-206.

CLÉMENT, V.

1999 Le territoire du Sud-Ouest de la péninsule Ibérique à I'époque romaine: du concepta u modele d'organisation de I'espace. In. GORGES, J.-G. et MARTÍN, G. (Orgs) Économie et territoire em Lusitanie remaine, Madrid: Casa de Velásquez: 109-120.

CORZO SÁNCHEZ, D. R.

1976 In finibus emeritensium. In.: BLANCO FREIJEIRO, A. (Org.) Augusta Emerita: actas del simposio internacional commemorativo del bimilenário de Mérida. Madrid: Dirección General del Patrimonio Artístico y Cultural del Ministerio de Educación y Ciencia/ Patronato de la ciudad de Mérida: 217-233.

ENRÍQUEZ NAVASCUÉS, J.

1997 La Merida prerromana y el poblamiento pre y protohistorico de su comarca. In.: Mérida: ciudad y patrimônio, n. 1: 29-43.

FARIA, A.

1998 Algumas questões em torno da fundação de Augusta Emerita. In.: Revista Portuguesa de Arquelogia, volume 1, numero 1: 161167.

2006 Novas Notas Historiográficas sobre Augus ta Emerita e outras cidades Hispano-romana. In.: Revista Portuguesa de Arqueologia, volume 9, numero 2: 211-237.

FERNANDO CORRALES, J.

1989 El território de Augusta Emerita e los límites entre la Bética y Lusitania. In.: XIX Congresso Nacional de Arqueologia, volume 1, Saragoza: 889-898.
FORNI, G.

1982 La popolazione di Augusta Emerita. In.: Homenaje a Saenz de Buruaga. Madrid: s/e.

1976 La tribu papiria di Augusta Emerita. In.: BLANCO FREIJEIRO, A. (Org.) Augusta Emerita: actas del simposio international commemorativo del bimilenario de Mérida. Madrid: Dirección General del Patrimonio Artistico y Cultural del Ministério de Educación y Ciencia/ Patronato de la ciudad de Mérida:33-42.

FRIAS, M.

1999 Guerra transhumancia y ocupación del território del Suroeste peninsular durante la Republica romana. In.: GORGES, J.-G. et MARTÍN, G. (Orgs.) Économie et territoire en Lusitanie romaine, Madrid: Casa de Velásquez.

GIL MANTAS, V.

2004 A Lusitânia e o Mediterrâneo: identidade e diversidade numa província romana. In.: Conimbriga, 43: 63-83.

GORGES, J.-G. ET MARTÍN, G. (ORGS.)

1999 Économie et territoire en Lusitanie romaine, Madrid: Casa de Velázquez.

JIMÉNEZ SALVADOR, J.L.

1992 Las ciudades hispanorromanas. In.: Cuadernos de Arte Español n 30, Historia 16. Madrid.

LE ROUX, P.

1999 Le territoire de la colonie auguste de Mérida: réflexions pour un bilan. In.: GORGES, J.-G. et MARTÍN, G. (orgs.) Économie et territoire en Lusitanie romaine, Madrid: Casa de Velázquez.

2004 Mérida Capitale de la Province Romaine de Lusitanie. In.: GORGES, J.-G., CERRILLO, E. Y BASARRATE, T. (ed) V Mesa Redonda Internacional sobre Lusitania Romana: Las comunicaciones (Cáceres, 2002) Madrid: Ministério da Cultura.

2006 Regarder vers Rome aujourd'hui. In.: Mélange de L'École Française de Rome, Antiguité, MEFRA118/1-, Roma: École Française de Rome: 159-166.

MARTÍN DE CÁCERES, E.

1988 La aplicación de las teorías de lugar central al territorio romano de Augusta Emérita. In.: BURILLO, F. et all. (org.) 
Espaço e poder no principado romano: um estudo de caso sobre a fundação da colônia de Augusta Emérita entre os séculos I e II d.C.

R. Museu Arq. Etn., São Paulo, n. 23, p. 79-94, 2013.

Arqueologia Espacial: seminário sobre Arqueologia Espacial. Lisboa/Tomar: Teruel: 197-204.

MONTENEGRO DUQUE, A.

1972 História de España - Edad Antigua I: España Prerromana. Madrid: Gredos.

NOGALES BASARRATE, T.; ÁlVAREZ MARTINÉZ, $\mathrm{J}-\mathrm{M}$.

2004 Programas decorativos del foro colonial de Augusta Emérita. 'El templo de Diana' - templo de culto imperial. In.: RAMALLO ASENSIO, S. (edt.) La decoración arquitectónica en las ciudades romanas de occidente. Múrcia: universidad de Murcia: 293-319.

2003 El teatro romano de Augusto Emerita. In.: MUSEO NACIONAL DE ARTE ROMANO El teatro Romano: la puesta en Escena. Mérida: Fundación 'la Caixa'/ Ayuntamiento de Zaragoza: 63-73. . (EDT. CIENTÍFICA).

2004 Augusta Emerita: territorios, espacios, imágenes y gentes en Lusitania Romana - Monografias Emeritenses 8. Mérida: Museo Nacional de Arte Romano. . RODRIGUEZ MARTÍN, F.

2004 El paisaje urbano de Augusta Emerita: reflexiones en torno al Guadiana y las puertas de acceso a la ciudad. In.: Revista Portuguesa de Arqueologia - volume 7. Número 2: 365-405.

SAÉNZ DE BURUAGA, J.

1976 La fundación de Mérida. In.: BLANCO FREIJEIRO, A. (Org.) Augusta Emérita: actas del simposio internacional commemorativo bimilenario de Mérida. Madrid: Dirección General del Patrimonio Artístico y Cultural del Ministério de Educación y Ciencia/ Patronato de la ciudad de Mérida: $19-32$.

SÁNCHES, A.; CORRALES, J.

2000 El proceso de Romanización de la Lusitania Oriental: la creación de asentamientos militares. In.: GORGES, J-G. e BASARRATE, N. Sociedad y cultura en Lusitania romana - IV Mesa Redonda Internacional. Mérida: Junta de Extremadura: 85-100.

SÁNCHEZ BARRERO, P.; GÓMEZ-NIEVEZ, B.

1998 Caminos Periurbanos de Mérida. In.: MATEOS CRUZ, P.; ALBA CALZADO, M., MÁRQUEZ PÉREZ, J. (Coor.) Mérida: exacavaciones arqueológicas. Mérida: Memoria: 549-569.

SILLIÉRES, P.

1990 Voies romaines et limites de provinces et de cites em Lusitanie. In.: Les Villes de Lusitanie Romaine:Hiérarchies et territoires (table ronde internationale $d u$ CNRS), Talence, le 8-9 décembre 1988. Paris: CNRS: 51-72.

1982 Centurarion et voie romaine au sud de Mérida: contribution a la delimitation de la Betique et de la Lusitanie. In.:______.(Org.) Melanges de la Casa de Velazquez. Publié avec Le concours du C.N.R.S. Tomo XVIII/1. Paris: Difusion de Boccard: 437-448.

TRILLMICH, W.

2005 Monumentalización del espacio publico emeritense como reflejo de la evolución histórica colonial: el ejemplo del teatro. In.: (Orgs.) BASARRATE, T. Augusta Emerita: territorio, espacios, imagenes y gentes en Lusitania Romana - Monografia Emeritense 8 , Mérida: M.N.A.R.

1993 Los tres foros de Augusta Emerita. In.: LEÓN, P. Coloquio Internacional Colonia Patricia Corduba - uma reflexion arqueológica. Cordoba: Universidad de Córdoba: 175-195.

1998 Las ciudades hisponoromanas: reflejos de la metrópoli. In.: Hispania el legado de Roma, septiembre-noviembre de 1998. Zaragoza: Ministério de Educación y cultura: 163-174. 